associated autoantibodies such as antissDNA, anti-Su and antinRNP. Therefore, we investigated other mineral oils and evaluated the mechanism of autoantibodies induction.

Methods Female BALB/cJ (4 weeks old) were used. At 3 months of age, target mineral oil (pristine and other mineral oils) was injected intraperitoneal of each mouse. After 3 months later from injection, we sacrificed mice and extracted peritoneal cells and spleen cells from mice, and evaluated autoantibodies induction. And we also evaluate the expression of Tcell, macrophage cells and B cells surface receptors (Tcell: CD28, ICOS, CD40L, PD1. Macrophage cell and B cell: ICOS-L, CD40, PD-L1).

Result

1. We indicated autoantibodies (Anti-nuclear, anti-ssDNA, anti$\mathrm{Su}$ and anti-nRNP antibody) in mouse injected pristane and other mineral oils.

2. We detected $\mathrm{CD} 3 \zeta$ chain reduction in $\mathrm{T}$ cell of mineral oil injected mouse.

3. Expression of all surface receptors (CD28, ICOS, CD40L, PD1) of T cell were increased.

On the other hand, Macrophage cell and B cell surface receptors (ICOS-L, CD40, PD-L1) were decreased.

Discussion Our study indicated that mineral oil (pristane and other mineral oils) induced autoantibody, and $\mathrm{CD} 3 \zeta$ chain was reduced like to human autoimmune disease. Concerning to $\mathrm{T}$ cell, $\mathrm{T}$ cell receptors were stimulated but $\mathrm{CD} 3 \zeta$ chain was decreased. And macrophage cell and B cell were suppressed. Therefore, Mineral oil could stimulate $\mathrm{T}$ cell and suppress macrophage cell and $\mathrm{B}$ cell. But $\mathrm{CD} 3 \zeta$ of $\mathrm{T}$ cell was reduced. We think these phenomena could relate to induction of autoantibodies.

\section{NANOPARTICLES CONCENTRATION IN FROZEN EXHALED BREATH CONDENSATE AS AN INTERNAL DOSE OF NANOMATERIALS EXPOSURE}

\footnotetext{
${ }^{1,2}$ Saou-Hsing Liou* ${ }^{2}{ }^{2}$ Chung-Ching Wang, ${ }^{1}$ Wei-Te Wu, ${ }^{3}$ Wen-Che Hou, ${ }^{4}$ Hui-Ling Lee. ${ }^{1}$ National Institute of Environmental Health Sciences, National Health Research Institutes; ${ }^{2}$ Division of occupational medicine, Department of Family and Community Medicine, TriService General Hospital, National Defense Medical Centre; ${ }^{3}$ Department of Environmental Engineering, National Cheng Kung University; ${ }^{4}$ Department of Chemistry, Fu Jen Catholic University
}

\subsection{6/oemed-2018-ICOHabstracts. 1171}

Introduction Exhaled breath condensate (EBC) is an emerging and noninvasive specimen allowing the study of lung processes. EBC could be an ideal biological matrix, as it could provide information about the deposited dose. The purpose of this study is to examine whether exhaled UFP in EBC could be correlated with exposure levels or surrogate of nanoparticle exposure.

Methods $18 \mathrm{TiO}_{2}$-exposed nanomaterial workers and 23 nonexposed controls were recruited from nanotechnology factories. A questionnaire was used to collect personal information. EBC was collected by an ECoScreen turbo (Viasys GmbH, Höchberg, Germany) and stored at $-80^{\circ} \mathrm{C}$ until analysis. The particle size-number distribution of ultrafine particles (PM0.1) were assessed in the EBC samples with the NanoSight LM10 HS system (Nanosight Ltd., Salisbury, UK) using the Nanoparticle Tracking Analysis (NTA) method. The results were expressed as average size $(\mathrm{nm})$ mode size $(\mathrm{nm})$ concentration ((x108 \#particles/mL), \% of UFP and particles number of UFP).

Result The average size of particles (nm) in $\mathrm{TiO} 2$ exposed worker was smaller than non-exposed workers. The concentration of particles $\left(\mathrm{x} 10^{8}\right.$ \#particles $\left./ \mathrm{mL}\right)$ in $\mathrm{TiO} 2$ exposed worker was higher than non-exposed workers. However, there was no significant difference between $\mathrm{TiO}_{2}$ exposed and controls in the average size $(\mathrm{nm})$, mode size $(\mathrm{nm})$, concentration $\left(\mathrm{x} 10^{8}\right.$ \#particles $/ \mathrm{mL}$ ), \% of UFP and particles number of UFP. But we found that the particles number of UFP in females was significantly higher than in males.

Discussion The possible reason for no association between nanomaterial exposure and particle concentration in $\mathrm{EBC}$ may be due to the storage of $\mathrm{EBC}$ in $-80^{\circ} \mathrm{C}$ refrigerator for a period of time which may induce aggregation or agglomeration of nanoparticles. Further study is required to clarify the use of exhaled UFP in fresh EBC as exposure matrix.

\section{VOC'S IN CONTAINER, STUDY OF HEALTH PROBLEMS IN 125 FRENCH DOCKERS}

1,2 D Lucas*, ' I Despres, ${ }^{1,2}$ D Jegaden, ${ }^{2,3}$ B loddé. 'Iroise Health Occupational service Brest France; ${ }^{2}$ French society of maritime Medicine Brest France; ${ }^{3}$ Center of Occupational Health and environmental Diseases Brest Teaching Hospital Brest France

\subsection{6/oemed-2018-ICOHabstracts. 1172}

Introduction The EOM society published four years ago, a specific questionnaire, FUMEX questionnaire, on health impact of fumigants and other VOC's in containers. The aims of this study were to evaluate exposure and health impact in dockers.

Methods Dockers are interviewed in face to face by a nurse or an occupational physician from Port occupational health centre of Le Havre and Brest from april to September 2015. Questionnaires were analysed by sphinx software.

Results 125 questionnaires were included and analysed. Mean age was 35 years, $46 \%$ were smokers. More than $80 \%$ declared not being exposed to fumigants or VOC's. Exposures were mostly described for refrigeration technicians (21\%), or during port engine driving, handling containers. Symptoms most frequently described were headaches (42\%), fatigue (50\%), sleeping disorders $(33,6 \%)$, and pulmonary irritation (31\%). Only $22.4 \%$ wore regularly protective equipment. Phosphine is the fumigant mostly mentioned.

Discussion Most exposed of port workers seem to be now refrigeration technicians and logistic workers. A lack of knowledge on risk and prevention's measures is evident and important. The FUMEX questionnaire is too complicated to be relevant for daily prevention in occupational health services. It's more needed for physicians or in hospital or researchers working with suspicious cases. A shorter and more comprehensible questionnaire was created.

\section{OCCUPATIONAL RISK FACTOR FOR LYMPHATIC OR HAEMATOPOIETIC CANCER: CASE-CONTROL STUDY USING OCCUPATIONAL CANCER MONITORING SYSTEM DATA}

SM Park*, JH Leem, HC Kim. INHA University Hospital, Incheon, South korea

10.1136/oemed-2018-ICOHabstracts.1173 
Introduction According to 2011 annual report of national cancer registration program, age-standardised incidence of non-hodgkin lymphoma, leukaemia, multiple myeloma, Hodgkin lymphoma is $6.8,5.0,1.4,0.5$ per $1,00,000$. Although incidence rate is low, social attention is increasing due to the fatality. While there has been many foreign studies on association between occupational risk factor and lymphatic, haematopoietic cancer, a study reflecting the domestic situation is insufficient. So we conducted casecontrol study using data from occupational cancer monitoring system to assess risk factor.

Methods Cases were 384 leukaemia, 523 non-hodgkin lymphoma, 218 multiple myeloma patients reported from occupational cancer monitoring system from 2011 to 2014. Controls were selected randomly matched on age, sex, residence. All participants were interviewed for lifestyle habits, exposure or occupational history of group1, group2A carcinogen. Analysis was performed using chi-square test primarily, and logistic regression to adjust for smoking status.

Results Analysing by chi-square test, excess risks were shown for exposure to benzene, formaldehyde, TCE, PAH in leukaemia, to benzene, formaldehyde, TCE in non-hodgkin lymphoma, to benzene, formaldehyde in multiple myeloma. Analysing by logistic regression to adjust for age, sex, smoking status, excess risk were shown for exposure to benzene, formaldehyde, pesticide in non-hodgkin lymphoma, to benzene in multiple myeloma. Other exposures were associated with lymphatic or haematopoietic cancer, but were not significant.

Conclusion Increased risk of lymphatic or haematopoietic cancer were associated with some occupations and chemicals. But other exposures showed no statistically significant association due to insufficient number of samples. There is a need for sufficient number of samples to obtain additional association between exposure and cancer risk.

\section{PREDICTION AND CHARACTERISATION OF BIOMARKER NETWORK FOR BENZENE EXPOSURE}

${ }^{1}$ MVC Santos*, ${ }^{1}$ AL Larentis*, ${ }^{2}$ JA Perini. 'National School of Public Health (ENSP) FIOCRUZ), Rio de Janeiro, RJ, Brazil; ${ }^{2}$ University of the Western Zone (UEZO). Rio de Janeiro, RJ, Brazil, RJ, Brazil

\subsection{6/oemed-2018-ICOHabstracts.1174}

Introduction Benzene is identified as a carcinogen. Long-term exposure to benzene causes haematological alterations, including an increased risk of acute myeloid leukaemia. However, the molecular mechanisms of Benzene systems effects remain poorly understood. Hence, a better understanding of the molecular mechanisms involved in this condition is a priority. Here, we employed a joint the integration of molecular networks, a gene-gene interaction database, biological processes analysis and functional annotation analysis to explore system effects for prioritising candidate genes to biomarkers to evaluate benzene exposure.

Methods We selected 96 genes targets with altered expression in occupational exposed to benzene (2009 to 2014). The analysis was performed using the multiple association network integration algorithm for predicting gene function, which identifies known gene-gene interactions among a genes list and provides additional genes. Topological properties of network were calculated by MCODE, BINGO and Centiscape,

Results A network of 114 genes and 2415 interactions were obtained. After topological analysis, a minor network composed by 16 nodes was identified, which is composed by most relevant nodes of major network. In this sub-network, KLF6, KLF4 and JUN are the most interconnected nodes, they being been considered a putative biomarker in which the exclusion of one node could produce a strong perturbation in the signalling network.

Conclusion The biological interaction network method presented probabilities of interactions between genes, demonstrating the potential of the use and application of the multiple association network integration algorithms for predicting gene function and for the observation of multiple genes in the system, using theoretical data to building clusters for identification of possible genes as biomarker.

\section{AUDITORY DYSFUNCTION IN WORKERS FROM A PRINTING PRESS EXPOSED TO ORGANIC SOLVENTS}

A Juarez, Aguilar, O Trujillo*, D Fierro, L Trejo, C Madriga. Occupational health research

\subsection{6/oemed-2018-ICOHabstracts.1175}

Introduction There are various chemical agents such as organic solvents (OS), which can cause hearing loss. The objective of this study was to determine the presence of auditory dysfunction in a mixture of DO and noise-exposed workers from a printing press.

Cross-sectional study was conducted including 176 from a printing press in Mexico City, exposed to noise and an OS mixturesWe categorised workers within 2 groups I. Exposed for $<10$ and II. Exposed $\geq 10$ years, we estimated hearing loss through a multiple linear regression model.

Results The mean age of group I was 32 \pm 9.3 [19-62] years and for group II was 41. 6 46.5 [29-58] years. The mean noise was $78.10 \pm 10.6 \mathrm{~dB} 58.1 \mathrm{~dB}$ and $93.8 \mathrm{~dB}$, group I. showed a threshold fall in the $4 \mathrm{kHz}$ up to $25 \mathrm{DB}$ in both ears, with an average recovery of $5 \mathrm{~dB}$ at $8 \mathrm{kHz}$ Right ear: $2000 \mathrm{~Hz}: \quad$ II $\beta=4.2 \quad(p=0.003), 4000 \quad \mathrm{~Hz}: \quad$ II $\beta=5.6$ $(p=0.002), 8000 \mathrm{~Hz}$ II $\beta=3.8(p=0.5)$; Left ear: $2000 \mathrm{~Hz}$ : II. $=4.1(\mathrm{p}=0.002), 4000 \mathrm{~Hz}$ : II $\beta=5.2(\mathrm{p}=0.006), 8000 \mathrm{~Hz}$ : II $\beta=5.2(p=0.002)$ the second model high frequencies $(2,4$, and $8 \mathrm{KHz})$ in right ear was II $\beta=4.4(\mathrm{p}=0.002)$ and in the left ear was II $\beta=4.8 \quad(\mathrm{p}<0.001)$.

Discussion Our studied population, showed an overall prevalence of auditory dysfunction of $3.94 \%$, group II was the most affected Workers with a concomitant exposure to noise and DO $>10$ years have a higher auditory dysfunction prevalence, compared with workers without exposure to these agents.

\section{INDUCTION OF METABOLIC SHIFT FROM GLYCOLYSIS TO PENTOSE PHOSPHATE PATHWAY IN HUMAN BLADDER CANCER CELLS EXPOSED TO BENZO[A] PYRENE}

${ }^{1,2}$ Nisha Verma*, ${ }^{1}$ Mario Pink, ${ }^{2,3}$ Albert W Rettenmeier, ${ }^{1}$ Simone Schmitz-Spanke. ${ }^{1}$ Institute
and Outpatient Clinic of Occupational, Social and Environmental Medicine, University of
Erlangen-Nuremberg, Germany; ${ }^{2}$ Institute of Hygiene and Occupational Medicine, University
Hospital Essen, Germany; ${ }^{3}$ Institute of Medicinal Informatics, Biometry and Epidemiology,
University Hospital Essen, Germany

10.1136/oemed-2018-ICOHabstracts.1176

Introduction Benzo[a]pyrene (B[a]P), a well-known polyaromatic hydrocarbon, is known for its lung carcinogenicity, however, its role in bladder cancer development is still discussed. The present 